\title{
Improved Dissolution of Poorly Water Soluble TD49, a Novel Algicidal Agent, via the Preparation of Solid Dispersion
}

\author{
Hyoung-Kyu Lee', Hoon Cho ${ }^{2}$ and Hyo-Kyung Han ${ }^{1+}$ \\ ${ }^{1}$ BK21 Project team, College of Pharmacy, Chosun University, Gwangju, Korea \\ ${ }^{2}$ Dept. of Polymer Science \& Engineering, Chosun University, Gwangju, Korea \\ (Received May 10, 2010 • Revised May 27, 2010 • Accepted May 28, 2010)
}

\begin{abstract}
S - The objective of this study was to improve the extent of drug release as well as the dissolution rate of TD49, a novel algicidal agent, via the preparation of solid dispersion (SD). Among the various carriers tested, Solutol ${ }^{\circledR}$ HS 15 was most effective to enhance the solubility of TD49. Subsequently, SDs of TD49 were prepared by using Solutol ${ }^{\circledR}$ HS15 and their solubility, dissolution characteristics and drug crystallinity were examined at various drug-carrier ratios. Solubility of TD49 was increased significantly in accordance with increasing the ratio of Solutol ${ }^{\circledR}$ HS15 in SDs. Compared to untreated powders and physical mixtures (PMs), SDs facilitated the faster and greater extent of drug release in water. Particularly, SD having the drug-carrier ratio of 1:20 exhibited approximately $90 \%$ of drug release within $1 \mathrm{hr}$. Differential scanning calorimetry (DSC) thermograms and X-ray diffraction (XRD) patterns suggested that SDs might enhance the dissolution of TD49 by changing the drug crystallinity to an amorphous form in addition to the increased solubilization of drug in the presence of Solutol ${ }^{\circledR}$ HS15. In conclusion, SD using Solutol ${ }^{\circledR}$ HS15 appeared to be effective to improve the extent of drug release and the dissolution rate of poorly water soluble TD49.
\end{abstract}

Key words - TD49, Algicides, Solubility, Dissolution, Solid Dispersion, Solutol

Harmful algal blooms (HABs) are natural phenomena caused by blooms of microscopic algae, which significantly affect the environment and the health of humans as well as aquatic life (Anderson, 2009; Zingone and Enevoldsen, 2000). Many HAB species produce toxins that are transferred through the food web, resulting in the harmful effect on humans and other organisms that consume them (Erdner et al., 2008; Sellner et al., 2003). Furthermore, non-toxic HABs also cause the severe damage to ecosystems and aquaculture, since the sheer biomass of the accumulated algae depletes oxygen levels through excessive respiration or decomposition (Erdner et al., 2008; Sellner et al., 2003). Recently, the frequency and severity of HABs appears to be increasing throughout the coastal areas of all continents and HABs becomes a world-wide problem (Sellner et al., 2003; Van Dolah, 2000). Therefore, there is an urgent and compelling need for controlling HABs.

To control the HABs, several methods have been proposed including the use of chemicals, clay particles, algicidal viruses or bacteria (Jancula et al., 2008; Lee et al., 2008; Meepagala et al., 2005; Sengco and Anderson, 2004; Van Hullebusch et al., 2002; Anderson, 1997; Nagasaki and Yamaguchi, 1997). For example, the potential use of clays to control the HABs has

†Corresponding Author:

Tel : +82-62-230-6364, E-mail : hkhan@chosun.ac.kr

DOI : 10.4333/KPS.2010.40.3.181 been explored to aggregate with HAB cells and carry them to bottom sediments (Sengco and Anderson, 2004). However, it requires considerable amount of preparatory studies to determine the fate of sedimented cells and toxins and the decomposition of sedimented biomass and resulting oxygen depletion (Sengco and Anderson, 2004; Anderson, 1997). Consequently, the use of clay should be limited due to its high costs and the possible harmful effects on marine organisms although it has been successful to some extent (Anderson, 1997). On the other hand, the application of algicidal chemicals is one of the most common methods to control the development of HABs, however, the use of chemicals is often limited by undesirable toxicity (Anderson, 2009; Schrader et al., 2003; Tucker, 2000; Nor, 1987). Therefore, the development of new algicidal compounds selectively effective against harmful algae is urgently needed.

As a large effort to develop the selective algicides, many derivatives of thiazolidinedione (TD) have been synthesized and subsequently TD49, a 5-(3-chloro-4-(cyclohexyloxy)benzylidene)thiazolidine-2,4-dione (Fig. 1), has been identified as a potent and selective inhibitor against harmful algae such as Heterosigma akashiwo and Cocholodinium polykrikoide (Kim et al., 2009). However, TD49 is poorly water soluble and it is necessary to improve its solubility to ensure further safety evaluation at high doses and also to maximize its effectiveness as a new algicidal drug. Therefore, for the solubilization of TD49, the present study aimed to prepare solid dispersions of 
<smiles>O=C1NC(=O)/C(=C/c2ccc(OC3CCCCC3)c(Cl)c2)S1</smiles>

Figure 1. Structure of TD49.

TD49 and evaluate its solubility as well as dissolution characteristics.

\section{Materials and Methods}

\section{Materials}

Polyethylene glycol 660 hydroxystearate (Solutol ${ }^{\circledR}$ HS15), Poloxamer 407 (Lutrol ${ }^{\circledR}$ micro 127 MP) and Povidone K-30 (Kollidon ${ }^{\circledR} 30$ ) were obtained from BASF (Ludwigshafen, Germany). Hydroxypropylmethyl cellulose (HPMC 2910) was obtained from Whawon Pharm Co. (Whasung, Korea). All other chemicals were of reagent grade and used without further purification. TD49 was provided by Dr. Hoon Cho (Chosun University, Gwangju, Korea) and its chemical structure was confirmed by ${ }^{1} \mathrm{H}$ NMR ((300 MHz, DMSO- $\left.d_{6}\right) \delta 12.59$ (s, 1H), $7.72(\mathrm{~s}, 1 \mathrm{H}), 7.70(\mathrm{~s}, 1 \mathrm{H}), 7.52(\mathrm{~d}, J=13.2 \mathrm{~Hz}, 1 \mathrm{H}), 7.37$ $(\mathrm{d}, J=13.2 \mathrm{~Hz}, 1 \mathrm{H}), 4.56-4.62(\mathrm{~m}, 1 \mathrm{H}), 2.03-2.50(\mathrm{~m}, 2 \mathrm{H})$, 1.69-1.86 (m, 2H), 1.51-1.54 (m, 2H), 1.35-1.45 (m, 4H).

\section{Carrier Screening}

Various carriers were examined for solid dispersion preparation with TD49. For this purpose, the solubility of TD49 was evaluated in the presence of various carriers $(1 \% \mathrm{w} / \mathrm{v})$ such as HPMC 2910, Poloxamer 407, Povidone K-30 and Solutol ${ }^{\circledR}$ HS15 as described in Solubility Study Section.

\section{Preparation of Physical Mixture and Solid Dispersions}

TD49 and Solutol ${ }^{\circledR}$ HS15 were dissolved in ethanol. The amount of ethanol varied depending on the drug-carrier ratios. After the complete dissolution, the solvent was removed under vacuum at room temperature. The resulting solid dispersion was scraped out with a spatula and dried under vacuum for 12 hrs. The weight ratios of drug to Solutol ${ }^{\circledR}$ HS15 were 1:5, 1:10 and 1:20. Physical mixtures (PMs) having different drug-carrier ratios were also prepared by simply mixing TD 49 and Solutol ${ }^{\circledR}$ HS15 using a spatula in a mortar.

\section{Solubility Studies}

Drug amount equivalent to $1 \mathrm{mg}$ of TD49 was dissolved in $1 \mathrm{~mL}$ of distilled water and stirring at $700 \mathrm{rpm}$ for $48 \mathrm{hrs}$ at room temperature. The samples were then centrifuged at $13000 \mathrm{rpm}$ for $10 \mathrm{~min}$ and filtered through $0.45 \mu \mathrm{m}$ pore-sized PTFE syringe filter and analyzed by HPLC.

\section{Differential Scanning Calorimetry (DSC) and Powder X-ray Diffraction (PXRD)}

Thermal analysis was carried out using a DSC unit (Pyris 6 DSC, Perkin Elmer, Netherlands). Indium was used to calibrate the temperature scale and enthalpic response. Samples were placed in aluminum pans and heated at a scanning rate of $10^{\circ} \mathrm{C} / \mathrm{min}$ from 20 to $200^{\circ} \mathrm{C}$, using nitrogen as a purge gas.

Samples were also evaluated by using an X-ray powder diffractometer (X'Pert PRO MPD, PANalytical Co., Holland).

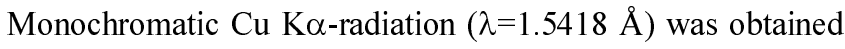
with a Ni-filtration and a system of diverging and receiving slides of $0.5^{\circ}$ and $0.1 \mathrm{~mm}$, respectively. The diffraction pattern was measured with a voltage of $40 \mathrm{kV}$ and a current of $30 \mathrm{~mA}$ over a $2 \theta$ range of $3-40^{\circ}$ using a step size of $0.02^{\circ}$ at a scan speed of $1 \mathrm{~s} /$ step.

\section{Dissolution Studies}

Dissolution studies were conducted using the USP paddle method at $50 \mathrm{rpm}$ using $300 \mathrm{~mL}$ of dissolution medium in a DST 600A dissolution tester (Fine Science Institute, Korea). Test samples containing drug amount equivalent to $6 \mathrm{mg}$ of TD49 was filled into hydroxypropyl methylcellulose (HPMC) capsules. Then, all samples were exposed to distilled water for $2 \mathrm{hrs}$ and samples were withdrawn at predetermined time points. After the each sample collection, an equivalent amount of fresh medium was added to maintain the constant volume of dissolution media. Samples were then filtered through $0.45 \mu \mathrm{m}$ pore-sized PTFE syringe filter. Filtered samples were analyzed by HPLC to determine the released drug amount. The experiment was performed in triplicates.

\section{HPLC Analysis}

TD49 concentration was analyzed by the HPLC assay. Rosiglitazone was used as an internal standard for the assay. The chromatographic system was consisted of a pump (LC10AD), an automatic injector (SIL-10A) and a UV detector (SPD-10A) (Shimadzu Scientific Instruments, Tokyo, Japan). An octadecylsilane column (Gemini C18, $4.6 \times 250 \mathrm{~mm}$, $5 \mu \mathrm{m}$; Phenomenex, Torrance, CA, USA) was eluted with a mobile phase consisting of $10 \mathrm{mM}$ phosphate buffer:acetonitrile $(25: 75, \mathrm{v} / \mathrm{v} \%, \mathrm{pH} 4.3)$. The flow rate was $1.0 \mathrm{~mL} / \mathrm{min}$ with the detection wavelength set at $320 \mathrm{~nm}$. The retention time of TD49 and the internal standard was $30 \mathrm{~min}$ and $5.7 \mathrm{~min}$, respectively. 


\section{Results and Discussion}

Numerous studies have demonstrated the preparation of solid dispersions with hydrophilic polymers as an effective approach to improve the dissolution of poorly water soluble drugs. For example, the incorporation of poloxamer 407 in solid dispersion of poorly water soluble nifedipine markedly increased the solubility of nifedipine and facilitated the faster and more complete dissolution (Chutimaworapan et al., 2000). Rajebahadur et al. (2006) also reported that solid dispersion of nifedipine using Solutol ${ }^{\circledR}$ HS15 increased the solubility and dissolution rate of nifedipine. The enhanced solubility and dissolution via the solid dispersion could be explained by the several factors such as drug solubilizing effect of hydrophilic carriers, better wettability of drug by the carrier and the change of drug crystallinity to amorphous form (Ahuja et al., 2007; Vasconcelos et al., 2007). Therefore, in the present study, enhanced solubility and drug release of TD49, a novel algicidal agent was attempted by the preparation of SDs with a hydrophilic carrier.

As summarized in Table I, among the tested carriers, Solutol ${ }^{\circledR}$ HS15 appeared to be most effective to markedly increase the solubility of TD49. As an effective solubilizer, Solutol ${ }^{\circledR}$ HS15 forms the loose and porous spherical micelles, which could be the reason for the high solubilizing capacity of Solutol $^{\circledR}$ HS15 for a wide range of drug. In addition, Solutol ${ }^{\circledR}$ HS15 exhibited low toxicity profile $\left(\mathrm{LD}_{50 / \mathrm{iv} / \mathrm{rat}}:>1.47 \mathrm{~g} / \mathrm{kg}\right.$, $\mathrm{LD}_{50 / \mathrm{oral} / \mathrm{rat}}$ : $\sim 20 \mathrm{~g} / \mathrm{kg}$ ) (Wade and Weller, 1994). Therefore, based on the favorable toxicity profile and also the high solubilizing capacity, Solutol ${ }^{\circledR}$ HS15 was selected as a hydrophilic carrier for the preparation of SDs of TD49 and then their solubility profiles were evaluated at different drug-carrier ratios. As illustrated in Fig. 2, solubility was enhanced by increasing the proportions of Solutol ${ }^{\circledR}$ HS15 in both PMs and SDs. Given that the critical micelle concentration (CMC) of Solutol ${ }^{\circledR}$ HS15 is $0.021 \%$ (w/v) (Buszello et al., 2000), the amount of Solutol ${ }^{\circledR}$ HS 15 in all tested PMs and SDs was above the critical micelle concentration. Therefore, there should be simultaneous increase in micelles concentration with the

Table I. Solubility of TD49 in Water (Mean \pm S.D., $n=3$ )

\begin{tabular}{cc}
\hline \hline Carriers $(1 \% \mathrm{w} / \mathrm{v})$ & Solubility $(\mu \mathrm{g} / \mathrm{mL})$ \\
\hline None & $0.836 \pm 0.152$ \\
Povidone K-30 & $2.06 \pm 0.64$ \\
HPMC 2910 & $7.74 \pm 2.67$ \\
Poloxamer 407 & $6.09 \pm 0.45$ \\
Solutol $^{\circledR}$ HS15 & $147 \pm 22.1$ \\
\hline
\end{tabular}

increase in Solutol ${ }^{\circledR}$ HS15 concentration. Overall, the solubility of solid dispersions was significantly higher than that of the physical mixtures. Particularly, at the weight ratio of 1:20, solubility of TD49 from solid dispersion was two times higher as compared to that of physical mixture. Those results suggest that in addition to the solubilizing effect of Solutol ${ }^{\circledR}$ HS15, the increase in solubility via the SD preparation should be explained by the change in drug crystallinity of TD49 in SDs. Therefore, the change in drug crystallinity was examined by DSC thermograms and PXRD patterns.

As shown in Fig. 3, the DSC curves of pure TD49 and Solutol ${ }^{\circledR}$ HS15 exhibited the characteristic endothermic peaks around $187^{\circ} \mathrm{C}$ and $30^{\circ} \mathrm{C}$, respectively, which corresponded to their intrinsic melting points. However, the distinctive endot-

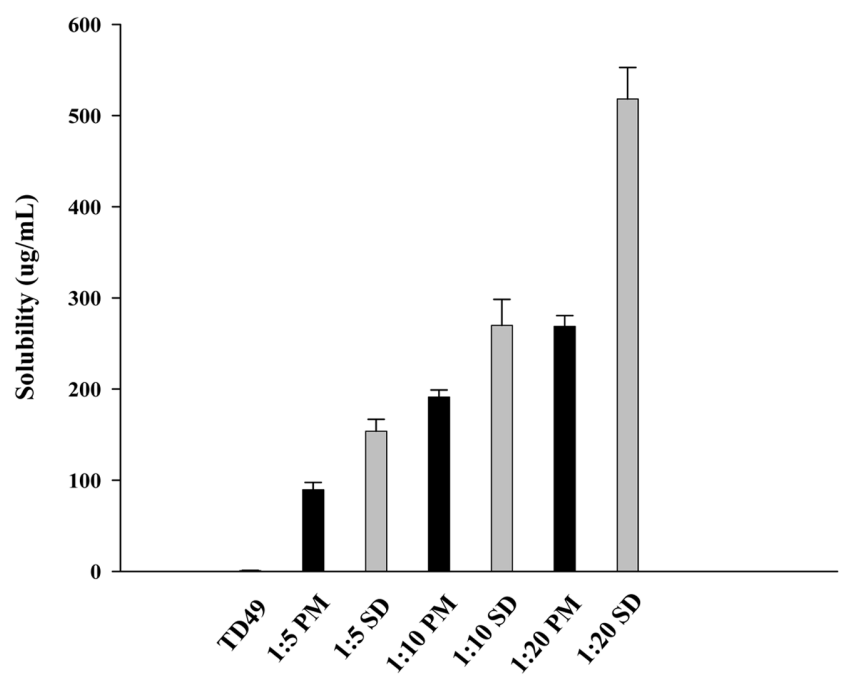

Figure 2. Solubility of TD49 in untreated powder, physical mixtures (PM) and solid dispersions (SD) with Solutol ${ }^{\circledR}$ HS15 at various weight ratios $(\mathrm{Mean} \pm \mathrm{SD}, \mathrm{n}=3$ ).

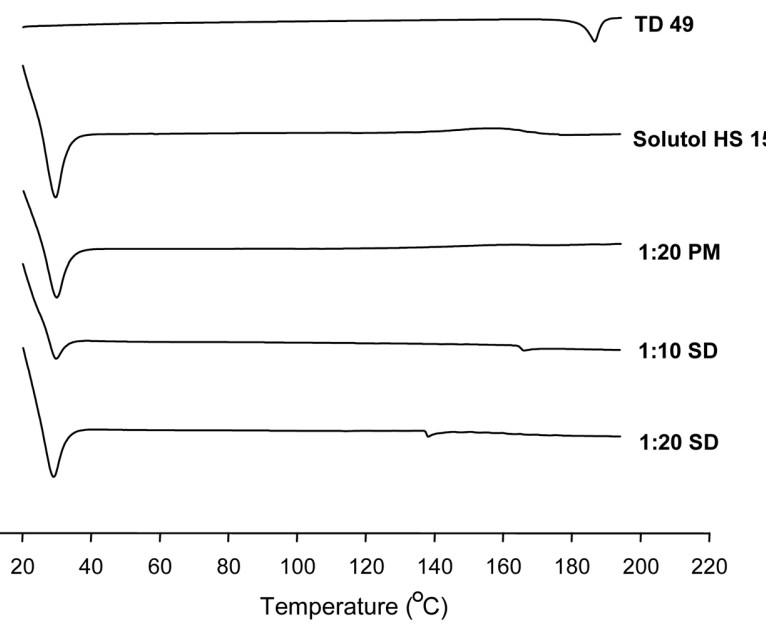

Figure 3. DSC thermograms of TD49, Solutol ${ }^{\circledR}$ HS15, physical mixture (PM) and solid dispersions (SD). 


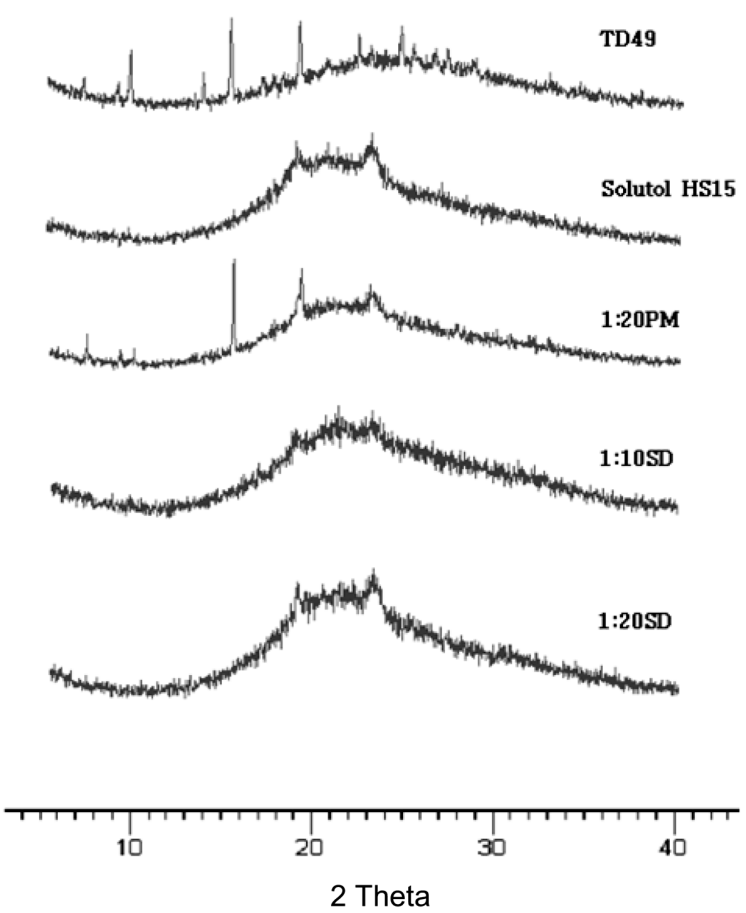

Figure 4. X-ray diffractograms of TD49, Solutol ${ }^{\circledR}$ HS15, physical mixture (PM) and sold dispersions (SD).

hermic peak of TD49 was not shown in SDs, implying that TD49 might have molecularly dispersed in the carrier. Interestingly, the DSC thermogram of PMs was similar to that of SDs. This result might be explained by the fact that TD49 in PM dissolved in the melted Solutol ${ }^{\circledR}$ HS15 when thermal analysis was performed and thus the melting peak of TD 49 disappeared.

Since DSC thermograms could not differentiate PMs from SDs, XRD studies were used to examine the crystallinity of TD49 in PMs and SDs. As shown in Fig. 4, pure TD49 has several dominant peaks at $2-\theta$ angles within $30^{\circ}$. Solutol ${ }^{\circledR}$ HS15 also has two characteristic peaks at $19.4^{\circ}$ and $23.4^{\circ}$. In case of 1:20 PM, although most of peaks disappeared, peaks at $7.8^{\circ}, 10.4^{\circ}, 15.8^{\circ}, 19.4^{\circ}$ and $23.4^{\circ}$ were still observed. Except for the peaks at $19.4^{\circ}$ and $23.4^{\circ}$ overlapped with the peaks of Solutol ${ }^{\circledR}$ HS15, peaks at $7.8^{\circ}, 10.4^{\circ}$ and $15.8^{\circ}$ came from the crystalline form of TD49, implying that TD49 in PM should be present in crystalline form. In contrast, characteristic peaks of TD49 completely disappeared in SDs, suggesting that TD49 was in amorphous form. Those results strongly supported that the improved solubility of SD formulation should be explained by the change of drug crystallinity into amorphous form in addition to the better wettability and micelle formation in the presence of Solutol ${ }^{\circledR}$ HS15.

The dissolution characteristics of SDs were also evaluated in

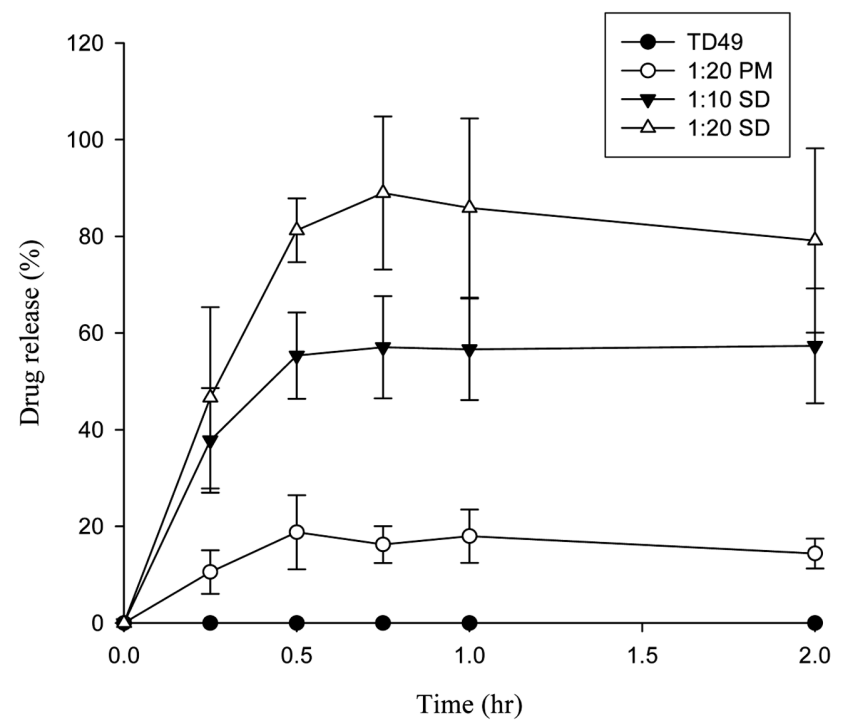

Figure 5. Dissolution profiles of TD49 from the untreated powder, physical mixture (PM) and solid dispersions (SD) with Solutol ${ }^{\circledR}$ HS15 in water $(50 \mathrm{rpm}$, Mean $\pm \mathrm{SD}, \mathrm{n}=3$ ).

water and compared to those of PM and untreated powder. As shown in Fig. 5, while pure TD49 remained practically undissolved in water for $2 \mathrm{hr}$, SDs promoted effectively the faster and greater dissolution of TD49. In the case of 1:20 SD, approximately $90 \%$ of drug release was observed within $1 \mathrm{hr}$. It also exhibited far greater drug release than the corresponding PM, suggesting that amorphous state of TD49 facilitated the extent of drug release as well as dissolution rate of TD49 in SDs. The enhanced dissolution of TD49 in PM compared to the untreated powder (pure TD49) could be explained by the increased solubilization of drug via the better wettability and the formation of micelles in the presence of Solutol ${ }^{\circledR}$ HS15 (Rajebahadur et al., 2006).

Collectively, the present study suggests that SDs might be useful to improve the solubility and dissolution of TD49. In general, the practical usefulness of SD formulations can be limited by the physicochemical instability, therefore, the stability of SDs and potential re-crystallization of TD49 during the storage should be assessed in further characterization.

\section{Conclusion}

Preparation of solid dispersion of TD49 with Solutol ${ }^{\circledR}$ HS15 appeared to be an effective approach to improve the extent of drug release as well as dissolution rate of poorly water soluble TD49, mainly via the change in drug crystallinity to amorphous form as well as the increased solubilization of drugs in the presence of Solutol ${ }^{\circledR}$ HS15. 


\section{Acknowledgment}

This research was supported by the Pioneer Research Center Program through the National Research Program of Korea funded by the Ministry of Education, Science and Technology (Grant No. M1071118001-08M1118-00110)

\section{References}

Ahuja, N., Katare, O.P., Singh, B., 2007. Studies on dissolution enhancement and mathematical modeling of drug release of a poorly water-soluble drug using water-soluble carriers. Eur. J. Pharm. Biopharm. 65, 26-38.

Anderson, D.M., 2009. Approaches to monitoring, control and management of harmful algal blooms (HABs). Ocean. Coast Manag. 52, 342-347.

Anderson, D. M., 1997. Turning back the harmful red tide. Nature 388, 513-514.

Buszello, K., Harnisch, S., Müller, R. H., Müller, B. W., 2000. The influence of alkali fatty acids on the properties and the stability of parenteral O/W emulsions modified with Solutol HS $15^{\circledR}$. Eur. J. Pharm. Biopharm. 49, 143-149.

Chutimaworapan, S., Ritthidej, G. C., Yonemochi, E., Oguchi, T., Yamamoto, K., 2000. Effect of water-soluble carriers on dissolution characteristics of nifedipine solid dispersions. Drug Dev. Ind. Pharm. 26, 1141-1150.

Erdner, D.L., Dyble, J., Parsons, M.L., Stevens, R.C., Hubbard, K.A., Wrabel, M.L., Moore, S.K., Lefebvre, K.A., Anderson, D.M., Bienfang, P., Bidigare, R.R., Parker, M.S., Moeller, P., Brand, L.E., Trainer, V.L., 2008. Centers for Oceans and Human Health: a unified approach to the challenge of harmful algal blooms. Environ. Health 7 (Suppl 2):S2, 1-17.

Jancula, D., Drábková, M., Cerný, J., Karásková, M., Korínková, R., Rakusan, J., Marsálek, B., 2008. Algicidal activity of phthalocyanines--screening of 31 compounds. Environ. Toxicol. 23, 218-223.

Kim, Y. M., Gajanan, G., Cho, H., Jin, E. S., 2009. Screening of various algicidal compounds against red tide microalgae; Heterosigma akashiwo, Chattonella marina and Cochlodinium polykrikoides. Abstracts, 2009 International Symposium \& Annual meeting, The Korean Society for Microbiology and Biothechnology, pp.315.

Lee, B.K., Katano, T., Kitamura, S., Oh, M.J., Han, M.S., 2008.
Monitoring of algicidal bacterium, Alteromonas sp. strain A14 in its application to natural Cochlodinium polykrikoides blooming seawater using fluorescence in situ hybridization. J. Microbiol. 46, 274-82.

Meepagala, K.M., Schrader, K.K., Wedge, D.E., Duke S.O., 2005. Algicidal and antifungal compounds from the roots of Ruta graveolens and synthesis of their analogs. Phytochemistry 66, 2689-2695.

Nagasaki, K., Yamaguchi, M., 1997. Isolation of a virus infectious to the harmful bloom causing microalga. Heterosigma akashiwo. Aquat. Microb. Ecol. 13, 135-140.

Nor, Y. M., 1987. Ecotoxicity of copper to aquatic biota: a review. Environ. Res. 43, 274-282.

Rajebahadur, M., Zia, H., Lee, C., 2006. Mechanistic study of solubility enhancement of nifedipine using vitamin E TPGS or solutol HS-15. Drug Delivery 13, 201-206.

Schrader, K.K., Nanayakkara, N.P., Tucker, C.S., Rimando, A. M., Ganzera, M., Schaneberg, B.T., 2003. Novel derivatives of 9,10-anthraquinone are selective algicides against the mustyodor cyanobacterium Oscillatoria perornata. Appl. Environ. Microbiol. 69, 5319-5327.

Sellner, K.G., Doucette, G.J., Kirkpatrick, G.J., 2003. Harmful algal blooms: causes, impacts and detection. J. Ind. Microbiol. Biotechnol. 30, 383-406.

Sengco, M.R., Anderson, D.M., 2004. Controlling harmful algal blooms through clay flocculation. J. Eukaryot. Microbiol. 51, 169-172.

Tucker, C.S., 2000. Off-flavor problems in aquaculture. Rev. Fish. Sci. 8, 45-88.

Van Dolah, F.M., 2000. Marine algal toxins: origins, health effects, and their increased occurrence. Environ. Health. Perspect. 108 (Suppl 1), 133-141.

Van Hullebusch, E., Deluchat, V., Chazal, P., Baudu, M., 2002. Environmental impact of two successive chemical treatments in a small shallow eutrophied lake. I: Case of copper sulfate. Environ. Pollut. 120, 627-634.

Vasconcelos, T., Sarmento, B., Costa, P., 2007. Solid dispersions as strategy to improve oral bioavailability of poor water soluble drugs. Drug Discov. Today 12, 1068-1075.

Wade, A., Weller, P. J., 1994. Handbook of Pharmaceutical Excipients $\left(2^{\text {nd }}\right.$ edition), Pharmaceutical Press, London.

Zingone, A., Enevoldsen, H.O., 2000. The diversity of harmful algal blooms: a challenge for science and management. Ocean. Coast. Manag. 43, 725-748. 